\title{
Urinary Tract Injuries in Low-Resource Settings
}

\author{
Mathias Onsrud \\ Oslo University Hospital, \\ Norway
}

\section{Introduction}

The purpose of this chapter is to elucidate some serious complications of hysterectomy when performed in low-resource countries. The main target is doctors intending to work under such conditions.

Urinary tract injuries are encountered in high-resource settings as well as in low-resource settings but comparative incidence data are lacking. Particular for low resource countries is the difficult situation under which the causative intervention was performed. Table 1 enumerates some general factors that can influence the risk of surgery. All of these factors may be present at the same time in the same place. Bleeding complications and postoperative infections are frequent. Conditions like HIV, tuberculosis and female genital schistosomiasis may intervene. A high prevalence of cervical cancer must be remembered. Factors relevant for the hysterectomy procedure in particular are: General anesthesia with muscle relaxation is seldom available; operations must be done in spinal anesthesia normally. Suitable instruments and equipment like suction and diathermia are often lacking. Minimal invasive procedures (laparoscopy, endoscopy) are seldom available.

Patient's nutritional status and co-morbidity

Disease stage and duration

Preoperative diagnosis and patient preparation

Laboratory facilities

Blood supply and antibiotics

Anesthesia

Surgeon's training and supervision

Instruments available

Postoperative service

Follow-up

Table 1. Factors influencing the operative risk in low-resource settings

\section{Types of urinary tract injuries}

Two main types of urinary tract injuries are encountered after hysterectomy: 1) bladder damage, with vesicovaginal fistula as the ultimate manifestation, and 2) ureteric damage, ranging from crushing to the most severe sequel, ureterovaginal fistulas. Probably, a large 
part of ureteric occlusions with hydronephrosis/renal damage pass undetected due to lack of awareness and diagnostic means.

\title{
1. Bladder damage
}

Incidental cystotomy most often occur during deliberation of the bladder from the uterus. Abnormal anatomy due to large uterine size and adhesions after pelvic inflammatory disease or cesarean sections can make dissection difficult. For benign hysterectomies, a $2.5 \%$ incidence of incidental cystotomies (34 of 1317 operations) has been reported (1) with a subsequent development of vesicovaginal fistula in $11.7 \%$ (4 out of 34 injuries). The main risk factor for this sequel is the extent of the injury, but large uterus, heavy blood loss and tobacco use may also be of importance (2).

\section{Ureteric damage}

For major gynecologic surgery, an average incidence of ureteric injuries of about $0.4 \%$ has been reported - 19 out of 4665 procedures (3). Data from low-resource countries are lacking, but the incidence is presumably higher there. Injuries are associated with both abdominal and vaginal hysterectomy, simple abdominal hysterectomy being most common. Operations on residual adnexae are at particular risk, as are those with large myomas, especially if located in the cervical part of uterus (4). The right ureter and the left ureter are equally affected. A common site of injury is near the pelvic brim, dorsal to the infundibulopelvic ligament. Injuries in the parametrial area are located at 1) the site where ureter crosses under the uterine artery, 2) in the tunnel towards the bladder ("tunnel of Wertheim"), or 3) in the intramural part of the bladder. These injuries are more difficult to detect and to handle. Lesions on the lateral pelvic sidewall are less frequent.

The severity of damage ranges from crushing, through ligation, transection, angulation to resection and fistula formation as late sequel (Table 2). Ischemic damage can appear if the ureter is dissected free from its adventitial sheath for several centimeters. It is remarkable though how well ureter can tolerate ischemia provided no postoperative radiation is added.

\author{
Crushing \\ Ligation \\ Angulation \\ Transection \\ Resection \\ Fistulation (late sequel)
}

Table 2. Types of operative ureteric injuries

\section{Urogenital fistula}

Urogenital fistula is the most important late sequel of an operative injury to the urinary tract. In developing countries the great majority of urogenital fistulas are obstetric ("the African fistula"). Long-standing, obstructed labor coupled with inadequate obstetric care is the main reason for this $(5,6)$. In comparison, fistulas considered to be complications to hysterectomy are relatively few. In Nigeria, $96.5 \%$ of fistulas were related to delivery (7). This contrasts with the situation in developed countries where the majority of fistulas are due to pelvic surgery, malignancy and severe inflammatory conditions. A group of surgeons 
with experience both from Turkey and Niger found gynecologic surgery to be the main cause of fistula in the former country and obstetric complications in the latter (8). A change during the later decades from a mainly obstetric to a mainly iatrogenic etiology has been reported from some developing countries $(9,10)$. The quality of obstetric care and surgical skills are important factors for this development.

\subsection{Data from the Democratic Republic of Congo}

Amongst 597 patients operated for urogenital fistulae at Panzi hospital from November 2005 till November 2007, 21 fistulas $(3.5 \%)$ were related to a previous hysterectomy $(11,12)$. Nine of these women $(42.9 \%)$ had a ureterovaginal fistula compared to 27 out of 567 women (4.8\%) in the obstructed labor group (OR 15, 95\%CI 5.8-38.7) (Table 3). Twelve $(57.1 \%)$ of the hysterectomy related fistulas were of the vesicovaginal type and located high up in the vagina, including one vesicocervical fistula after a subtotal hysterectomy. Vesicovaginal fistulas located in the lower part of vagina or involving urethra or its sphincter were not seen among the hysterectomy associated cases but were frequent in the obstructed labor group, $36.7 \%$ (208 of 567). None of the hysterectomy associated fistulas were surrounded by fibrosis or had a fistula size of more than $2 \mathrm{~cm}$ as compared to $64 \%$ with scar fibrosis and $34 \%$ with size more than $2 \mathrm{~cm}$ for those caused by obstructed labor. This indicates that the hysterectomy related fistulas had a "cleaner" origin.

\begin{tabular}{|c|c|c|c|c|c|c|c|}
\hline \multirow{3}{*}{ Cause } & \multirow{2}{*}{\multicolumn{2}{|c|}{$\begin{array}{l}\text { All } \\
\text { Fistulas }\end{array}$}} & \multicolumn{5}{|c|}{ Type of urogenital fistula } \\
\hline & & & \multirow{2}{*}{$\begin{array}{c}\text { VVF } \\
\text { low } \\
\mathrm{N}\end{array}$} & \multirow{2}{*}{$\begin{array}{l}\text { VVF } \\
\text { high } \\
\mathrm{N}\end{array}$} & \multirow{2}{*}{$\begin{array}{l}\text { VUF } \\
\mathrm{N}\end{array}$} & \multirow{2}{*}{$\begin{array}{c}\text { UrVF } \\
\text { N }\end{array}$} & \multirow{2}{*}{$\begin{array}{c}\text { Comb- } \\
\text { inations } \\
\mathrm{N}\end{array}$} \\
\hline & $\mathrm{N}$ & $(\%)$ & & & & & \\
\hline Obstructed labor & 567 & $(95.0)$ & 208 & 285 & 34 & 27 & 13 \\
\hline \multicolumn{8}{|l|}{ Hysterectomy } \\
\hline Emergency peripartum & 9 & $(1.5)$ & & 4 & $1^{*}$ & 4 & \\
\hline $\begin{array}{l}\text { Abdominal, for benign } \\
\text { gynecologic disease }\end{array}$ & 9 & $(1.5)$ & & 5 & & 4 & \\
\hline $\begin{array}{l}\text { Vaginal, for benign } \\
\text { gynecologic disease }\end{array}$ & 3 & $(0.5)$ & & 2 & & 1 & \\
\hline Sexual violence, infections & 9 & $(1.5)$ & 5 & 4 & & & \\
\hline Total & 597 & $(100)$ & 213 & 300 & 35 & 36 & 13 \\
\hline$\%$ & & & 35.6 & 50.3 & 5.9 & 6.0 & 2.2 \\
\hline
\end{tabular}

VVF vesicovaginal fistula, VUF vesicouterine fistula, UrVF ureterovaginal fistula

*vesicocervical fistula after subtotal hysterectomy

Table 3. Urogenital fistulas by cause and type. Panzi Hospital, Democratic Republic of Congo 2006-2007 (from ref.12)

Nine of the 21 postoperative fistulas $(42.9 \%)$ appeared in women who had undergone an emergency peripartum hysterectomy. The indication for these hysterectomies is unknown. High median age (35 years) and the high median parity (8) make postpartum hemorrhage or poor uterine contractility probable, although uterine rupture cannot be excluded. 
Nine women had undergone abdominal hysterectomy for uterine myomas and 3 had vaginal hysterectomy performed as part of an operation for pelvic organ prolapse. For these patients with a gynecologic reason for the hysterectomy, the median age was 40 years and median parity 5 , as compared to 22 years and parity 1 , respectively, for women with fistula caused by obstructed labor (Table 4 ).

\begin{tabular}{|c|c|c|}
\hline Cause of fistula/type of operation & $\begin{array}{l}\text { Median age } \\
\text { (years) }\end{array}$ & Median parity \\
\hline Obstructed labor - vaginal delivery $(n=226)$ & 22 & 1 \\
\hline \multicolumn{3}{|l|}{ Hysterectomy $(\mathrm{n}=21)$} \\
\hline Emergency, peripartum $(n=9)$ & 35 & 8 \\
\hline $\begin{array}{l}\text { Abdominal or vaginal, non-obstetric indication } \\
(\mathrm{n}=12)\end{array}$ & 40 & 5 \\
\hline
\end{tabular}

Table 4. Median age and parity at time of fistula appearance by cause (derived from ref. 12)

\subsection{Diagnosis}

Vesicovaginal fistulas are normally visible high up in the vagina. Direct inspection for fistula is done after filling the bladder with diluted methylene blue. Dye will immediately be observed in the vagina or on a tampon left there ("tampon test"). Cystoscopy will confirm the fistula. Its localization in relation to the ureteric openings is of importance for planning of the operation. Sometimes, only sutures perforating the bladder mucosa or granulation tissue are observed.

Ureteric occlusion can be caused by inadvertent ligation giving ureteric stenosis and hydronephrosis. Symptomes can be flank pain or slow postoperative recovery only. This condition can pass undetected or be diagnosed late after permanent renal damage is induced. Sonography - an important diagnostic tool in low-resource countries - can be of great help. Intravenous pyelo-uretero-graphy and vesicography are available at some places whereas this is rarely the case for CT-scans and MRI.

Ureteric lacerations are generally detected early, about $50 \%$ of during operation and $50 \%$ during the first 2 weeks postoperatively. $(3,4)$. Pain from uroplania or urine in the peritoneal cavity may appear, and sonography is then helpful. Urinary leakage through the vaginal top is more common. Creatinin measurement can be necessary to prove that the secretion really is urine. Dye inserted into the bladder will normally not leak to the vagina and cystoscopy is most often negative. Lack of urine secretion or intravenously infused dye from one of the ureteric openings is highly suggestive. Dye secretion to the vagina is confirmative. The ureterovaginal fistula is often not directly visible in the vagina.

\subsection{Causative interventions and prevention}

The types of hysterectomy covered in this chapter are those where urinary tract complications tend to occur most frequently: Emergency peripartum hysterectomy, abdominal hysterectomy and vaginal hysterectomy. Laparoscopic hysterectomy is seldom done under low-resource settings and will not be covered here. 
1. Emergency peripartum hysterectomy

Injury to the urinary tract is a common complication to peripartum hysterectomy. The most important risk factors for emergency cesarean hysterectomy are reported to be: uterine rupture, postpartum hemorrhage, cervical tears, placenta accreta and placenta previa. Previous cesareans and multiparity (para $>5$ ) increase the risk by 6.9 and 3.4, respectively (13). The risk factors mentioned are all commonly encountered in developing countries.

Uterine rupture represents a serious health problem with high maternal and perinatal mortality. In the least developed countries, rates up to $1 \%$ have been reported (14). In developed countries, most cases are scar ruptures related to a previous cesarean section, whereas in Sub-Saharan Africa 75\% are associated with an unscarred uterus (14). Here, the basis for rupture is mainly cephalopelvic disproportion. A typical scenario is that the first baby was delivered stillborn after a long-lasting, obstructed labor and the following pregnancy ends up with a uterine rupture. Other risk factors for rupture are abnormal presentations and multiparity (14). Populations with a high cesarean delivery rate - and thereby a high prevalence of scarred uterus - are at risk. The consequences for future pregnancies can be disastrous if these women are living in areas with poor access to emergency obstetric service. In areas with an increasing cesarean section rate, more uterine scar ruptures has been observed (15).

Obstructed labor is a common indication for cesarean section and few of the operations are planned. Cesarean delivery should protect against maternal mortality and morbidity and save the child. Nevertheless, $50 \%$ of women treated for fistula at Panzi hospital got their fistula despite a cesarean section was performed and $84 \%$ of the babies were stillborn. It is evident that in many cases, some form of assisted vaginal delivery would have been more appropriate. Unfortunately, the use of vacuum extraction has become rare and the cesarean delivery rate has increased in many areas $(15,16)$. Fear of vertical HIV transmission is one factor for this development, lack of obstetrical training is another (12).

Most cases of uterine rupture are treated by hysterectomy. This major surgery is risky for patients in a bad general condition. Further, the loss of uterus and fertility has serious social consequences in many societies. Suturing, with or without sterilization, can be a safe alternative and has been used in more than $60 \%$ of cases in some reports $(17,18)$. Additional ligature of the internal iliac arteries is sometimes necessary, and this technique should be known (19). A conservative approach necessarily implies that future pregnancies are strictly followed up of and a cesarean delivery performed in due time.

Postpartum hemorrhage accounts for $34 \%$ of maternal mortality in developing countries compared to $13 \%$ in developed countries (20) and is an important indication for emergency hysterectomy. The most common causes are uterine atony $(80 \%)$, retained placental fragments, genital tract lacerations and uterine rupture. Risk factors include a history of post partum hemorrhage or retained placenta, placental abruption, placenta praevia, uterine fibroids, hydramnios, multiple pregnancies, prolonged labor and instrumental delivery. Although an assessment of risk factors is important, post partum hemorrhage typically occurs unpredicted and all parturients are at the risk. Prompt handling is essential. Peripartum hysterectomy - cesarean or postpartum - can be a life saving procedure, although difficult and risky. The cervical edges can be difficult to identify and damage to vagina, bladder and ureters often occur. A supracervical hysterectomy is much less 
dangerous and should be preferred. When removal of the cervix is necessary endocervical palpation will to help identify the cervical edges and avoid injuries.

Conservative management of postpartum hemorrhage should be tried before hysterectomy is considered. Access to uterotonics, iv fluids, blood transfusion and curettage is essential. Balloon tamponade of uterus has become an important conservative method (21). A simplified condom method is useful in low-resource settings (22). The B-Lynch suture technique (23) is a effective measure to obtain compression of an atonic uterus during cesarean delivery. Cervical tears detected postpartum should be explored and sutured by the vaginal approach. In case of high tears and extrauterine hemorrhage, hysterectomy can be necessary.

A cesarean section performed late - in the second stage of labor - when the lower uterine segment is stretched and the bladder lifted high up, can easily lead to lacerations of cervix and vagina due to difficult access to the presenting part. Bleeding and difficulties may entail inappropriate suturing that can affect both the bladder and ureters, or cause inadvertent lacerations of these organs. The reversed breech extraction procedure of an entrapped fetus is a method to diminish the risk of tears and the risk of peripartum hysterectomy (24).

\section{Abdominal hysterectomy}

The incidence of pelvic organ fistula after hysterectomy ranges from 0.1 to $4 \%$ in different studies $(25,26)$. A higher incidence is reported after radical hysterectomy compared with hysterectomy on benign indications. In a nationwide cohort study of 182,641 hysterectomies from Sweden, 220 urogential fistulas $(0.12 \%)$ were registered. Laparoscopic hysterectomy was associated with the highest rate of fistula surgery, and subtotal abdominal hysterectomy was associated with the lowest. Risk factors are age, adhesions and postoperative infections. Risk factors for urinary tract damage are basically the same in lowresource countries as in high-resource countries. Spinal anesthesia commonly used in developing countries, gives poor relaxation. Large myomas, a common indication for hysterectomy in those areas, make access to the pelvis particularly difficult, especially when the myomas are located in the cervical part. Dislocation of organs and difficulties in identification of the bladder and ureteres increase the risk of accidental damage.

Cervical cancer is also very common in the developing world, in many countries the most common malignancy in women. This disease is most often detected in an advanced and inoperable stage. Many cancer patients undergo, however, a hysterectomy trial which, due to parametrial involvement and bleeding, ends up with a urinary tract injury. Operable (stage Ib-IIa) patients should preferably have a radical hysterectomy (a.m. Wertheim) which include proper identification and dissection of the bladder and ureteres. If this operation method is not available, or operability cannot be assured, the treatment of choice is radiotherapy with concomitant chemotherapy whenever available. Radical vaginal trachelectomy as fertility sparing operation for early stage cervical cancer has the same risk of ureteric injury as radical hysterectomy although the rate of bladder injury is higher (27).

The risk of urinary tract damage highly depends on the indication and type of intervention performed. Operations for endometriosis and malignancy (with radical hysterectomy) run a higher risk. In many cases, no predisposing factor is identified. Attempt to obtain hemostasis is the most common activity leading to injury (27). Preoperative measures like iv 
pyelogram, computed tomography, prophylactic ureteric stint have not shown to be preventive. The best prevention is that the surgeon always is aware of where the ureters is and stay safely away from it and preserving its adventitial sheath. Ureter should be visualized, not only palpated. The surgeon should know well the retroperitoneal approach and use it in all difficult cases. Special care should be taken when thermocautery is used.

\section{Vaginal hysterectomy}

Most vaginal hysterectomies are performed as part of a treatment for genital organ prolapse. Bladder and ureter injuries related to vaginal operations occur in all parts of the world. Register data from Finland showed an incidence of 0.2 bladder injuries per 1000 vaginal hysterectomies and the same incidence for ureteric injuries (1). Sixty-five percent of the complications were fistulas. In a series from France urinary tract injury occurred in $1.7 \%$ of 3076 vaginal hysterectomies - 54 bladder lesions and 1 ureteric lesion (28). It is reason to believe that the incidence of injury is higher in low-resource countries. Some institutions tend to performed hysterectomy also in cases with less pronounced genital organ prolapse. High incidence of cervical cancer and contraceptive need may be reasons for a liberal attitude to hysterectomy. However, the Manchester technique with cervical amputation is a less risky procedure. Recurrence and vault prolapsed are best prevented by building up the posterior part of the pelvic floor.

Age, parity, body weight and mode of delivery are known risk factors (1.28) and are common for low-income and high-income countries. Multiparity, poor general condition and chronic infections are more prevalent in developing countries. High bacterial content in the vagina and particular inflammatory conditions like urogenital schistosomiasis and tuberculosis may be predisposing factors. Bladder damage should be avoided by careful dissection and ureters should be localized by palpation against a metal retractor in the paravesical space (27).

\section{Treatment}

\section{Bladder injuries}

Most bladder lesions are detected during the operation. The bladder wall should be closed in two layers with nonperforating, absorbable sutures and an indwelling urinary catheter for 5 days. The ureteric ostia should be located. When the lesion is in its proximity, temporary insertion of a ureteric stint is advisable. Normally, the lesion will be cured without sequel.

Vesicovaginal fistulas caused by abdominal hysterectomy are located high up in vagina (Table 3). The vaginal approach for repair may be possible even for high located fistulas. In developing countries, this way tends to be chosen for reasons of anesthesia and fear of postoperative intestinal problems. In the Panzi hospital material, 5 out of 11 vesicovaginal fistulas after hysterectomy were operated vaginally. The abdominal approach may be technically easier and safer, especially in cases of pelvic adhesions, and implies a possibility of interposing an omental flap between the closed bladder wall and the vaginal wall to reduce the risk of recurrence. 
Some small, vesicovaginal fistulas can be managed conservatively by bladder drainage for some weeks. Fistula surgery can be a delicate procedure and every surgeon intending to start such activity should obtain adequate training at a fistula center. Valuable handbooks are available $(27,29)$.

Certain principles for urogenital fistula surgery prevail: 1)The tissue operated on should be without necrosis or inflammation. If operation is not done within 5 days after the injury, it is better to wait 6 weeks or more until tissue reaction is resolved. 2) All scar tissue around the fistula is removed by deliberate dissection, 3) All sutures must be tension-free. For suture technique, see fig. 1. 4) The ureteric ostiae should be visualized during the operation and, especially when the vaginal approach is used, ureteric stints applied to protect the ureters against incidental ligation or injury. 5) Postoperatively, free urine drainage must be assured for at least 2 weeks using a urethric or a suprapubic catheter. 6) Before departure, complete fistula closure is asserted by vaginal inspection after insertion of dye in the bladder
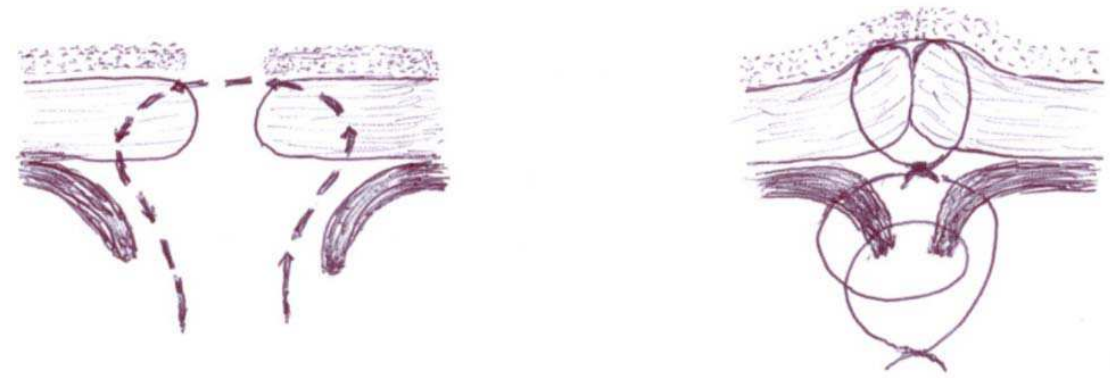

Fig. 1. Suture technique

Ureteric injuries

Ureteric occlusion should be diagnosed as early as possible before renal function is impaired. Time can be gained by temporary urinary deviation through percutaneous pyelostomy. This option is rarely available in low-resource settings. Immediate reoperation should be considered, provided the patient's general condition allows it and renal function is still possible to save. Any misplaced ligature or angulation should be removed, the viability of the ureter assessed and a stint placed through cystoscopy.

A partial transsection is repaired over a ureteral stint. Transection in upper or middle third is treated by uretero-ureterostomy over a ureteral stint. Some resection of the ureter ends can be necessary to assure viability, especially in cases of thermal injury. Spatulation of the ends is recommended to increase the lumen. The anastomosis must be completely tension free. Dissection must be done with care bearing in mind that blood supply to the ureter above the pelvic brim is coming from the medial side, below the prim from the lateral side. When the ureteric transsection took place less than $6 \mathrm{~cm}$ from the bladder vascularity is often impaired and primary anastomosis thereby risky. Transection of the lower third of the ureter is therefore most often treated by uretero-neocystostomy with Psoas hitch over a ureteric stint (27).

Once a ureterovaginal fistula has developed there is no longer an emergency situation. Renal function is normally not affected and a planned intervention can be performed. An 
abdominal, extraperitoneal approach is normally possible and preferable. The bladder is freed from its areolar attachment in the retropubic space and an extensive mobilization (almost 270 degrees) of its ventral surface performed. The bladder is elongated toward the Psoas tendon where it is fixed. The affected ureter is freed, transected as low as possible, and the stinted proximal end is anastomozed to the elongated bladder (27). All cases of ureterovaginal fistulas reported from Panzi Hospital (Table 3) were successfully treated by this method of uretero-neocystostomy.

All urogenital fistulas - iatrogenic as well as obstetric ones - should preferably be treated at a specialized fistula center. It is essential that the first operation is optimally performed. The chance of closure is greatly diminished after several attempts of repair (10).

\section{Conclusions}

Low-resource settings influence the risk of getting urinary tract injury as a complication to hysterectomy. Emergency peripartum hysterectomy is particularly risky and subtotal hysterectomy is a safer procedure. Postpartum hemorrhage should be managed conservatively whenever possible. Ureterovaginal and high located vesicovaginal fistulas are common sequels. These fistulas are smaller in size, have less scar tissue and appear in women with higher age and parity than the more common obstetric fistula. Repair is more often done through the abdominal route and should be performed at a specialized fistula center.

\section{References}

[1] Härkki-Sirén P, Sjöberg J, Tiitinen A. Urinary tract injuries after hysterectomy. Obstet Gynecol 1998;92(1):113-118.

[2] Duong TH, Gellasch TL, Adam RA. Risk factors for the development of vesicovaginal fistula after incidental cystotomy at the time of a benign hysterectomy. Am J Obstet Gynecol 2009;201(5):512.e1-4.

[3] Goodno JA, Powers TW, Harris VD. Ureteral injury in gynecologic surgery: A ten-year review in a community hospital. Am J Obstet Gynecol 1995;172(6):1817-1822.

[4] Preston JM. Iatrogenic ureteric injury: common medicolegal pitfalls. Brit J Urol Int 2000;86(3):313-317.

[5] Wall LL. Obstetric vesicovaginal fistula as an international public-health problem. Lancet 2006;368(9542):1201-1209.

[6] Muletta M, Rasmussen S, Kiserud T. Obstetric fistula in 14,928 Ethiopian women. Acta Obstet Gynecol Scand 2010;89(7):945-951.

[7] Wall LL, Karshima JA, Kirschner C, Arrowsmith SD. The obstetric vesicovaginal fistula: characteristics of 899 patients from Jos, Nigeria. Am J Obstet Gynecol 2004;190(4):1011-1019.

[8] Savan K, Ekin M, Kupelioglu L, Oral S. Surgical repair of genitourinary fistulae: comparison of experience at Turkey and Niger. Arch Gynecol Obstet 2010;282(6):649-653.

[9] El-Lamie IK. Urogenital fistulae: changing trends and personal experience of 46 cases. Int Urogynecol J Pelvic Floor Dysfunct 2008;19(2):267-272. 
[10] Elkins T. Fistula surgery: past, present and future directions. Int Urogynecol J 1997;8(1):30-35.

[11] Sjøveian S, Vangen S, Mukwege D, Onsrud M. Surgery outcome of obstetric fistula: a retrospective analysis of 595 patients. Acta Obstet Gynecol Scand 2011;90(7):753760.

[12] Onsrud M, Sjøveian S, Mukwege D. Cesarean delivery-related fistula in the Democratic Republic of Congo. Int J Gynecol Obstet 2011;114(1):10-14.

[13] Sheiner E, Levy A, Katz M, Mazor M. Identifying risk factors for peripartum cesarean hysterectomy. A population based study. J Reprod Med 2003;48:622-626.

[14] Hofmeyr GJ, Say L, Gülmezoglu AM. Systematic review: WHO systematic review of maternal mortality and morbidity. BJOG 2005;112(9):1221-1228.

[15] Onsrud M. Changed attitude to obstetrical delivery help in Eastern Congo (in Norwegian). Tidsskr Nor Legeforen 2008;128(9):1078-1080.

[16] Fauveau V. Is vacuum extraction still known, taught and practiced? A worldwide KAP survey. Int J Gynecol Obstet 2006;94(2):185-189.

[17] Sheth SS. Results of treatment of rupture of the uterus by suturing. BJOG 1968;75(1):5558.

[18] Klungsøyr P, Kiserud T. Rupture of the uterus treated by suture. Acta Obset Gynecol Scand 189;68(1):1-2.

[19] Joshi V, Otiv S, Majumder R, Nikam Y, Shrivastava M. Internal iliac artery ligation for arresting postpartum haemorrhage. BJOG 2007;114:356-361.

[20] Khan KS, Wojdyla D, Say L, Gulmezoglu AM, Van Look PF. WHO analysis of causes of maternal death: a systematic review. Lancet 2006;367:1066-1074.

[21] Georgiou C. Baloon tamponade in the management of postpartum hemorrhage: a review. BJOG 2009;116(6):748-757.

[22] Akhtar S, Begum MR, Kabir Z, Rashid M, Laila TR, Zabeen F. Use of condom to control massive postpartum hemorrhage. MedGenMed 2003;5(3):38.

[23] Ferguson JE, Bourgeois FJ, Underwood PB. B-Lynch suture for postpartum hemorrhage. Obstet Gynecol 2000;95(6):1020-1022.

[24] Chopra S, Bagga R, Keepanasseril A, Jain V, Kalra J. Disengagement of the deeply engaged fetal head during cesarean section in advanced labor: Conventional method versus reverse breech extraction. Acta Obstet Gynecol Scand 2009;88(10):1163-1166.

[25] Forsgren C, Lundholm C, Johansson AL, Cnattingius S, Altman D. Hysterectomy for Benign Indications and Risk of Pelvic Organ Fistula Disease. Obstet Gynecol 2009;114(3):594-599.

[26] Forsgren C, Altman D. Risk of pelvic organ fistula in patients undergoing hysterectomy. Curr Opin Obstet Gynecol 2010;22(5):404-407.

[27] Montz FJ, Bristow RE, Del Carmen MG. Operative injuries to the ureter. In: Rock JA, Jones HW, eds. Te Linde's Operative gynecology, ninth edition. Philadelphia: Lippincott Williams \& Wilkins, 2003:1081-1097. ISBN-10: 0781772346

[28] Mathevet P,Valencia P, Cousin C, Mellier G, Dargent D. Operative injuries during vaginal hysterectomy. Eur J Obstet Gynecol Reprod Biol 2001;97(1):71-75.

[29] First steps in vesico-vaginal fistula repair. Hancock B, ed. London: Royal Society of Medicine Press, 2005. ISBN 1-85315-611-6 


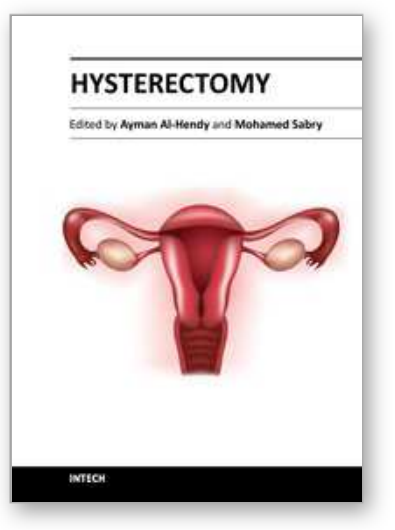

\author{
Hysterectomy \\ Edited by Dr. Ayman Al-Hendy
}

ISBN 978-953-51-0434-6

Hard cover, 426 pages

Publisher InTech

Published online 20, April, 2012

Published in print edition April, 2012

This book is intended for the general and family practitioners, as well as for gynecologists, specialists in gynecological surgery, general surgeons, urologists and all other surgical specialists that perform procedures in or around the female pelvis, in addition to intensives and all other specialities and health care professionals who care for women before, during or after hysterectomy. The aim of this book is to review the recent achievements of the research community regarding the field of gynecologic surgery and hysterectomy as well as highlight future directions and where this field is heading. While no single volume can adequately cover the diversity of issues and facets in relation to such a common and important procedure such as hysterectomy, this book will attempt to address the pivotal topics especially in regards to safety, risk management as well as pre- and post-operative care.

\title{
How to reference
}

In order to correctly reference this scholarly work, feel free to copy and paste the following:

Mathias Onsrud (2012). Urinary Tract Injuries in Low-Resource Settings, Hysterectomy, Dr. Ayman Al-Hendy (Ed.), ISBN: 978-953-51-0434-6, InTech, Available from:

http://www.intechopen.com/books/hysterectomy/urinary-tract-injuries-in-low-resource-settings

\section{INTECH}

open science | open minds

\section{InTech Europe}

University Campus STeP Ri

Slavka Krautzeka 83/A

51000 Rijeka, Croatia

Phone: +385 (51) 770447

Fax: +385 (51) 686166

www.intechopen.com

\section{InTech China}

Unit 405, Office Block, Hotel Equatorial Shanghai

No.65, Yan An Road (West), Shanghai, 200040, China

中国上海市延安西路65号上海国际贵都大饭店办公楼405单元

Phone: +86-21-62489820

Fax: +86-21-62489821 
(C) 2012 The Author(s). Licensee IntechOpen. This is an open access article distributed under the terms of the Creative Commons Attribution 3.0 License, which permits unrestricted use, distribution, and reproduction in any medium, provided the original work is properly cited. 